\title{
Phenological shifts and flower visitation of 185 lowland and alpine species in a lowland botanical garden
}

\author{
Mialy Razanajatovo ${ }^{1}$ (D) Christine Föhr ${ }^{2,3,4} \cdot$ Mark van Kleunen $^{1,5} \cdot$ Markus Fischer $^{2,3,4}$
}

\begin{abstract}
Many plant species respond to climate change by phenological shifts, usually with an earlier flowering onset. However, the variability in flowering responses to changed climatic conditions is large, and rare plant species, which are likely to have a low environmental tolerance, may be less able to shift their phenology than common ones. If plant species respond to climate change by shifting their flowering phenology, plant-pollinator interactions may become disrupted. However, it is vital for the reproduction of animal-pollinated plants, and thus for long-term population survival, that plants can attract pollinators. This might be especially difficult for rare species as they may depend on one or few pollinator species. To assess how climatic conditions affect the phenology of common and rare plant species, and whether the plant species attract potential pollinators, we assessed flowering onset and flower visitation in the lowland Botanical Garden of Bern, Switzerland, for 185 native plant species originating from different altitudinal zones. Plants from high elevations flowered earlier and showed more pronounced phenological shifts than plants from lower elevations, independent of species rarity. The probability, number, and duration of flower visits and the number of flower-visitor groups were independent of the altitudinal zone of plant origin and of species rarity. The composition of flower-visitor groups did also not depend on the altitudinal zone of plant origin and on species rarity. Thus, rare and common alpine plants may generally respond to climate change by an earlier flowering onset, and may be able to establish novel interactions with pollinators.
\end{abstract}

Keywords Commonness and rarity $\cdot$ Global warming $\cdot$ Mutualism $\cdot$ Novel interactions $\cdot$ Plant-pollinator interactions

Mialy Razanajatovo

mialy.razanajatovo@uni-konstanz.de

1 Ecology, Department of Biology, University of Konstanz, Universitätsstrasse 10, 78457 Konstanz, Germany

2 Institute of Plant Sciences, University of Bern, Altenbergrain 21, 3013 Bern, Switzerland

3 Botanical Garden Bern, University of Bern, Altenbergrain 21, 3013 Bern, Switzerland

4 Oeschger Centre for Climate Change Research, University of Bern, Falkenplatz 16, 3012 Bern, Switzerland

5 Zhejiang Provincial Key Laboratory of Plant Evolutionary Ecology and Conservation, Taizhou University, Taizhou 318000, China

\section{Introduction}

Current climate has rapidly changed, and the ongoing climate change affects ecosystems and species worldwide (IPCC 2007). Many plant species respond to climate change by distributional and phenological shifts (Parmesan 2006; Parmesan and Yohe 2003); the latter is most apparent in an earlier flowering onset (Fitter and Fitter 2002). The timing of flowering is important for animal-pollinated plants, because flowering at the wrong time can negatively affect seed production (Burgess et al. 2007) due to possible temporal mismatches between flowering and pollinator activity (Memmott et al. 2007). Therefore, adjusting flowering phenology to changing climatic conditions can be essential for the persistence of plant populations (Anderson et al. 2012).

Although many plant species shift towards earlier flowering at higher temperatures, several studies reported large variability in species responses (CaraDonna et al. 2014; Diez et al. 2012; Gugger et al. 2015). Other studies have identified life-history traits (e.g., lifespan), abiotic drivers (e.g., frost 
and drought), and biotic drivers (e.g., pollinators and competition) as factors influencing phenological responses of plant species to changing climate (Forrest and Miller-Rushing 2010; Wolkovich et al. 2014). Mechanisms that allow species to shift their flowering phenology are phenotypic plasticity and evolutionary change (Anderson et al. 2012; Matesanz and Valladares 2014; Parmesan 2006).

Because phenotypic plasticity should be selected for in populations inhabiting temporally and spatially variable environments (Baythavong and Stanton 2010; Chevin and Hoffmann 2017; Lázaro-Nogal et al. 2015), the high temporal and spatial environmental heterogeneity in alpine habitats might select for high plasticity in plants. Consequently, alpine and montane plants might flower earlier than colline (lowland) plants when grown in a lowland site. On the other hand, alpine plants with high plasticity in flowering onset might be more exposed to a risk of freezing damage when flowering early in response to temperature (Rixen et al. 2012). Due to an adaptation to alpine environments, plants from high elevations might, therefore, have a lower degree of plasticity in flowering phenology than plants from lower elevations (Delnevo et al. 2017; Gugger et al. 2015; Schmid et al. 2017). Given these seemingly contradicting views, it is important to test across multiple species whether alpine and montane plants flower earlier than colline plants when grown in a lowland site.

Changes in climatic conditions might differently affect the flowering phenology of plants from different climatic ranges. Because the ability to plastically respond to changes in the environmental conditions should allow plants to express advantageous phenotypes in a broad range of habitats, plasticity might be related to ecological niche breadth (Sultan 2001). In line with this, species experiencing a large variation in climate should have evolved larger climatic tolerance (Climate variability hypothesis; Sheth and Angert 2014). Therefore, due to a lack of plasticity, species with a narrow climatic tolerance might particularly be vulnerable to changing climate, whereas those with a larger climatic tolerance might be more resilient (Sheth and Angert 2014). A reduced ability to shift flowering phenology might also result in narrow climatic tolerance and rarity of species. If rare species fail to adjust phenologically to a warmer climate, their persistence might be severely threatened. However, we are not aware of any study that has explicitly tested whether the ability of rare species to shift their flowering phenology is lower than that of common species, and whether that of species from narrower climatic ranges is lower than that of species from larger climatic ranges.

If plant species and their pollinators do not manage to track their ideal climatic conditions in exactly the same way, vital mutualistic species interactions might become disrupted, and plant reproduction might be impeded (Kudo and Ida 2013; Memmott et al. 2007; Petanidou et al. 2014).
It is, however, also possible that novel plant-pollinator interactions develop (Burkle et al. 2013; Petanidou et al. 2008). Studies investigating the ability of species to integrate into novel plant-pollinator networks are still rare and most often concern non-native plant species (Memmott and Waser 2002; Razanajatovo et al. 2015; Vilà et al. 2009). Furthermore, studies investigating whether rare native species can establish novel plant-pollinator interactions are lacking altogether. It has been suggested that plant species should evolve pollinator specialization when they are rare to increase the probability that removed pollen is deposited on the stigma of a conspecific plant (Orians 1997). It could, however, also be that species are rare, because they require specialized pollinators (Phillips et al. 2014). On the other hand, rare plant species are expected to evolve specialization to the most common pollinators (Sargent and Otto 2006), and specialized plants have been found to be associated with generalist pollinators (Bascompte et al. 2006). Whether rare and common plant species differ in their ability to form new plant-pollinator interactions needs to be studied.

For a total of 185 native plant species, including common and rare species from different altitudinal zones in Switzerland, we analyzed measures of flowering onset, which we had recorded in the lowland Botanical Garden of Bern in 2011, in combination with flower visitation of the same individuals in the same year. We addressed the following questions:

1. Do alpine and montane plants start to flower earlier than colline (lowland) plants under warmer climatic conditions in the lowland?

2. Are shifts in flowering phenology more pronounced for common than for rare plant species, and for species from large climatic ranges than for species from small climatic ranges?

3. Does the ability to attract flower visitors outside the natural range differ between rare and common plant species?

\section{Methods}

\section{Study site and data collection}

In summer 2011, we assessed the onset of flowering and observed flower visitors on 185 native plant species, originating from different altitudinal zones in Switzerland, in the Botanical Garden of Bern, Switzerland $\left(46.95^{\circ} \mathrm{N}, 7.44^{\circ} \mathrm{E}\right.$; Table S1). While we had used the counts of flower visits on the 185 native species in a previous study (Razanajatovo et al. 2015) to compare them with 261 exotic species, we combine them here with unpublished flowering onset data to compare native species originating from different altitudinal 
zones and to compare rare and common native species. The Botanical Garden is situated at an elevation of 501-537 m, i.e., in the colline (lowland) altitudinal zone. It has an average annual rainfall of $1028 \mathrm{~mm} /$ year and a mean annual temperature of $8.1^{\circ} \mathrm{C}$. Outdoors, it harbors about 4500 plant species on a total area of 2.5 ha.

Once a month during the growing season (on 24-Mar, 19-Apr, 24-May, 27-Jun, 29-Jul, and 29-Aug-2011), we recorded all insect-pollinated plant species that had started flowering. When at least one plant of each species was flowering in the garden, we considered that the species had started flowering. For each species, we measured characteristics likely to determine how conspicuous and attractive they are for flower visitors. We estimated the total area that each of these plant species covered (i.e., abundance) and the number of flower units per $\mathrm{m}^{2}$ (i.e., flower-unit density). A flower unit was defined as one or more flowers from which an insect has to fly to reach the next unit (Dicks et al. 2002), e.g., one capitulum with multiple flowers of an Asteraceae species was considered to be one flower unit. Furthermore, as pollinator activity may differ between sunny and shaded spots, we recorded the exposure of the plants to direct sunlight at the moment of observation (yes/no). We also recorded the sections in the botanical garden in which each species was growing.

During each census, we observed 20-45 plant species that were recorded to have started flowering a few days before. Because flower-visitor activity depends strongly on the weather and the time of day, we carried out each census on a sunny day and within the time frame of approximately $2 \mathrm{~h}$ in the early afternoon (c. $1 \mathrm{pm}-3 \mathrm{pm}$ ). On each flowering species, a team of 7-15 volunteers (students, lab members, and colleagues from other research labs) observed ten flower units, if available, simultaneously for $15 \mathrm{~min}$. If there were fewer than ten flower units available, we noted the number of observed flower units, so that we could account for this in the analyses. We counted all flower visitors that made contact with reproductive organs of the observed flower units, and thus were likely to be pollinators. We assigned the flower visitors to broad taxonomic groups (ants, bee flies, bees, beetles, bumblebees, butterflies, flies, hover flies, moths, and wasps), and recorded the number of visits and the duration of visits.

\section{Climatic, flowering, and distributional variables}

We compared our data on the onset of flowering in the garden with literature data on the flowering period in nature (Landolt et al. 2010) to calculate a potential phenological shift in units of months. We considered the whole flowering period in nature to take natural variation in flowering onset into account. As an indicator value for the climate of the natural occurrence of each species, we used the Landolt
T-indicator value (Landolt et al. 2010), which characterizes the average air temperature during the growth period of each species of the Swiss flora. It largely corresponds with the altitudinal vegetation zone, where a species occurs (Landolt 2003). For example, $T$ values of $4,4.5$, and 5 correspond, respectively, to the colline zone, the warm colline zone and the very warm colline zone (Landolt et al. 2010). Each species is associated with one $T$ value and the range of variation of its $T$ value (small or large). Landolt et al. (2010) qualified climatic variation as "small" when a species occurs at most in one altitudinal zone beyond its $T$ value, and as "large" when a species occurs at least in three altitudinal zones but occupying at most $2 / 3$ of the total variation. Species with a small range of $T$ values occur only occasionally in the other altitudinal zones, while species with a large range of $T$ value frequently occur in the other altitudinal zones (Landolt et al. 2010). We also obtained the range of variation of the T-indicator value for each species as a proxy for climatic tolerance (Landolt et al. 2010). The observed plant species in the botanical garden had an altitudinal zone of origin that ranged from 1 (alpine and nival zone) to 5 (very warm colline zone). Because the Botanical Garden of Bern is in the colline zone ( $T$ value of 4 ), climatic distance was largest for plant species from the alpine and nival zone ( $T$ value of 1$)$. Species altitudinal zone of origin ( $T$ value) and range of $T$ values were not correlated (Pearson's $r=-0.003, p=0.968$ ). As a proxy for rarity or commonness of the plant species, we grouped them according to their status in the Red List for Switzerland (Moser et al. 2002): threatened (vulnerable, endangered or critically endangered) and not threatened (least concern and near threatened). Accordingly, we classified 45 of the 185 species (24\%) as rare (threatened).

\section{Data analysis}

\section{Flowering phenology}

To assess how the natural altitudinal range, climatic tolerance and rarity of a species influence the month of flowering onset in the Botanical Garden of Bern, we first fitted a linear mixed model using the lmer function of the lme 4 package (Bates et al. 2015) in the R software, version 3.1.2 (R Core Team 2012). We included the T-indicator value (1-5), the range of the T-indicator value and rarity as fixed terms. We also included the interaction of T-indicator value with rarity to assess whether the flowering phenology of rare and common plant species is differently affected by novelty of the climatic conditions. To account for potential differences in phenological responses due to variation in population size among the species observed in the botanical garden, we also included the area covered by the species as a fixed term. To account for potential variation due to species locations in the botanical garden, we grouped the locations, where the 
species grew in the garden into four main sections, and used it as a random factor. To account for taxonomy, we included family as an additional random factor. We tested the significances of the fixed terms using log-likelihood ratio tests (Zuur et al. 2009).

To analyze whether the natural altitudinal range, climatic tolerance, and rarity of species influence the shift in flowering phenology, we fitted an ordered logistic regression with a three-level response of the calculated difference between the month of recorded flowering onset in the garden and the flowering period given in the literature. The three levels of the response were: flowering 2 or more months earlier, flowering 1 month earlier, no change. The explanatory variables were the same as in the analysis of flowering onset. For this analysis, we used the polr function of the MASS package (Venables and Ripley 2002) in the R software. We tested the significances of the fixed terms using log-likelihood ratio tests.

\section{Flower visitation}

To assess whether plant species growing outside their natural altitudinal range are able to successfully attract potential pollinators, we fitted linear and generalized linear mixed-effect models using the lmer, glmer, and glmer.nb functions of the lme4 package in the R software. Our response variables were whether a plant species received flower visits or not (binomial distribution), the number of insect visits (negative binomial distribution), the number of flower-visitor groups (Poisson distribution), and the duration of visits per visited flower unit (Gaussian distribution) during the 15-min observation period. We log-transformed the duration of insect visits to ensure a Gaussian distribution of the residuals. As a fixed term, to account for some species having fewer than ten observed flower units, we fitted the number of observed flower units before rarity and T-indicator value, except in the model analyzing the number of visits, where we included $\log$ (number of observed flower units) as an offset. We also included $\log$ (total area covered by the species), $\log$ (number of flower units per $\mathrm{m}^{2}$ ) and exposure to direct sun as fixed terms, as these factors might influence the attractiveness to flower visitors. To reduce collinearity and to facilitate comparisons among estimates, we centered and scaled the covariates to a mean of zero and a standard deviation of one (Schielzeth 2010). We accounted for variation among the six census dates by including date as a random term in all models. To account for variation due to species locations in the botanical garden, we also used location as a random factor. In addition, we included plant family as a random factor to account for taxonomy. We tested the significances of the fixed terms using log-likelihood ratio tests.

To test whether the probability of visits by different flower-visitor groups differ among plant species from different altitudinal zones and between common and rare plant species, we performed a multinomial logistic regression (Ntzoufras 2011) in WinBugs (Lunn et al. 2000). As a multi-categorical response variable, we included the number of each flower-visitor group (ants, bee flies, bees, beetles, bumblebees, butterflies, flies, hoverflies, moths, and wasps). As an explanatory variable, we included the interaction between altitudinal zone and rarity (common vs. rare). We grouped plant species with $T$ values from 1 to 2.5 (alpine to lower subalpine distribution), 3 to 3.5 (montane and lower montane distribution), and 4 to 5 (colline to very warm colline distribution) together to obtain three sufficiently large categories. To account for taxonomy, we added plant family as a random term in the model. To account for variation due to different observation dates, we also included the census date as a random term.

\section{Results}

\section{Flowering phenology}

Month of flowering onset did not differ significantly between rare and common species (Table 1). Although month of flowering onset in nature was not significantly correlated with the T-indicator value ( $p=0.117$; Fig. S1), month of flowering onset in the botanical garden was positively correlated with the T-indicator value (Fig. 1a). This indicates that plants naturally growing at high elevations flowered earlier when grown at low elevation (Table 1; Fig. 1a). Plants from higher elevations also showed more pronounced phenological shifts than plants from lower elevations when both are grown at low elevation, as plants that started flowering 2 or more months earlier in the lowland garden than in their natural habitat had low T-indicator values typical for alpine species (Fig. 1b). The 19 species that showed a large phenological shift of 2 or more months had $T$ values from 1 to 2.5, i.e., they were all alpine and subalpine species (Fig. 1b). The plants that flowered 1 month earlier than in their natural habitat and the ones that did not show a shift in flowering onset had higher T-indicator values typical of montane and colline distributions, respectively (Table 2; Fig. 1b). The area covered by the observed species in the botanical garden did not significantly influence month of flowering onset (Table 1).

Species climatic range (variation of $\mathrm{T}$ ) had a significant effect on whether the species had undergone a phenological shift in flowering onset (Table 2). Of the 19 plant species that underwent a large phenological shift, 18 plant species had a small climatic range $(=94.7 \%)$. Of the plant species that underwent a 1-month shift ( $n$ $=30$ ), the ones with a small climatic range represented $66.7 \%$. The majority of the species underwent no shift 
Table 1 Results of a linear mixed effects model testing how altitudinal plant origin assessed as temperature indicator value $\mathrm{T}(1=$ alpine and nival zone, $2=$ subalpine zone, $3=$ montane zone, $4=$ colline zone, $5=$ very warm colline zone) and its range of variation, rarity, and area covered by the species influence flowering onset of 185 plant species in a lowland botanical garden

\begin{tabular}{llll}
\hline Response variable & \multicolumn{2}{l}{ Month of flowering onset } & \\
\cline { 2 - 4 } Fixed factor & df & $\chi^{2}$ & 0 \\
\hline Area covered by the species & 1 & 0.993 & 0.183 \\
Rarity & 1 & 0.043 & 0.319 \\
Species climatic range (variation of T) & 1 & 8.453 & 0.835 \\
T-indicator value & 1 & 0.012 & 0.004 \\
Rarity x T-indicator value & 1 & Std dev resid & 0.914 \\
\hline Random factor & Std dev & 1.223 & 185 \\
\hline Family & 0.947 & 1.223 & 185 \\
Location & 0.396 & & \multirow{2}{*}{} \\
\hline
\end{tabular}

Shown are degrees of freedom, ${ }^{\chi^{2}}$ values and $p$ values from log-likelihood ratio tests

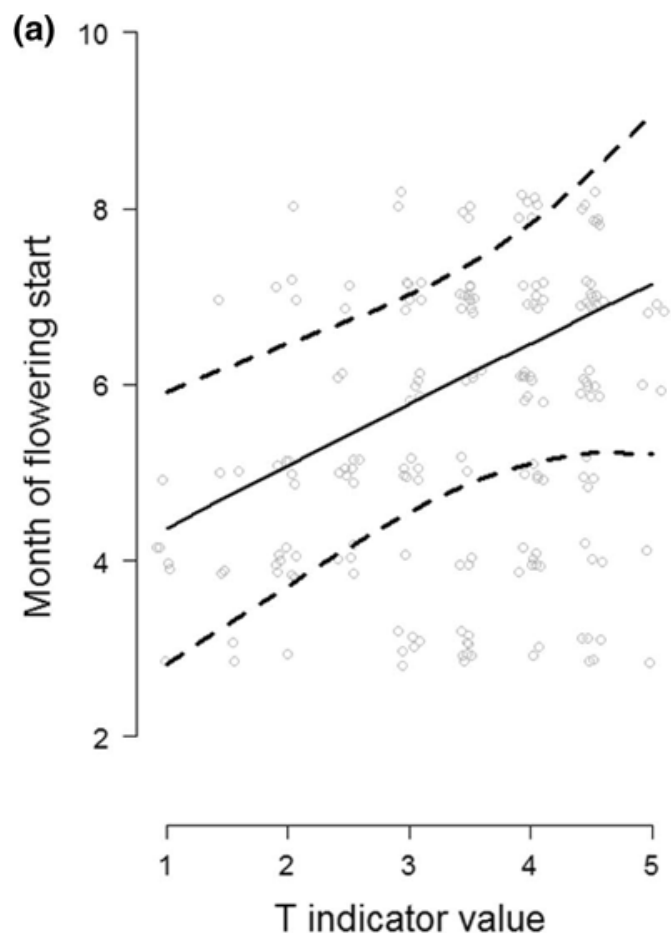

Fig. 1 Effect of altitudinal plant origin assessed as temperature indicator value $\mathrm{T}$ ( $1=$ alpine and nival zone, $2=$ subalpine zone, $3=$ montane zone, $4=$ colline zone, $5=$ very warm colline zone), on (a) flowering phenology and (b) phenological shifts of plants in a botanical

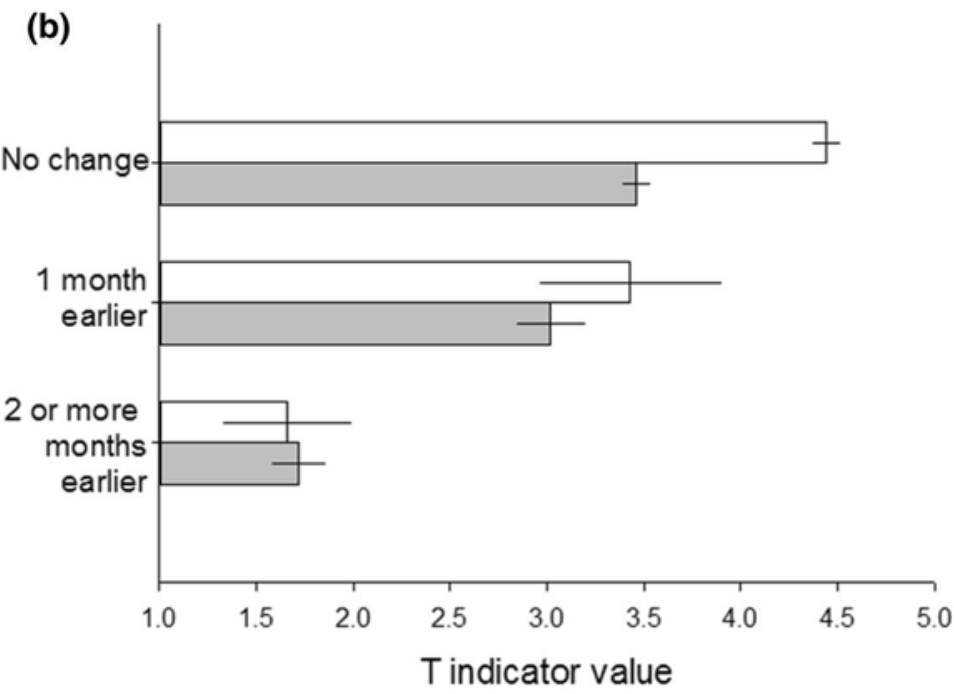

garden. Shown are (a) the regression line with 95\%-confidence intervals and (b) means and standard errors of rare species (empty bars) and common species (filled bars) based on individual species values $(n=136)$, and among those, $61.8 \%$ had a small climatic range. The area covered by the observed species in the botanical garden did not significantly influence phenological shift (Table 2).

\section{Flower visitation}

We observed a total of 1751 flower visits during the six census dates. Independent of the rarity of the plant species, 
Table 2 Results of an ordinal logistic regression testing how altitudinal plant origin assessed as temperature indicator value $\mathrm{T}(1=$ alpine and nival zone, $2=$ subalpine zone, $3=$ montane zone, $4=$ colline zone, $5=$ very warm colline zone) and its range of variation, rarity, and area covered by the species influence phenological shifts of 185 plant species in a lowland botanical garden

\begin{tabular}{|c|c|c|c|}
\hline \multirow{2}{*}{$\begin{array}{l}\text { Response variable } \\
\text { Fixed factor }\end{array}$} & \multicolumn{3}{|c|}{ Phenological shift } \\
\hline & $\mathrm{df}$ & $x^{2}$ & $p$ \\
\hline Area covered by the species & 1 & 2.189 & 0.139 \\
\hline Rarity & 1 & 0.773 & 0.379 \\
\hline Species climatic range (variation of $\mathrm{T}$ ) & 1 & 4.149 & 0.042 \\
\hline T-indicator value & 1 & 53.094 & $<0.0001$ \\
\hline Rarity x T-indicator value & 1 & 0.005 & 0.942 \\
\hline
\end{tabular}

Shown are degrees of freedom, ${ }^{\chi 2}$-values and $p$ values from log-likelihood ratio tests

the probability of insect visits, the number of flower visits $($ mean $=9.1)$, the duration of the individual visits (mean $=18.5 \mathrm{~s})$, and the number of flower-visitor groups (mean $=1.5$ ) were not affected by the altitudinal zone of plant origin (T-indicator value; Table 3). Plant species with small climatic ranges, however, were significantly less likely to receive visits (Table 3 ).

Bees were the most abundant flower visitors in the botanical garden. They accounted for $54.1 \%$ of all flower visits and visited $61.0 \%$ of all observed plant species (Fig. S2). Common and rare species from different altitudinal zones were equally likely to be visited by all eight flower-visitor groups (ants, bee flies, bees, beetles, bumblebees, butterflies, flies, hover flies, moths, and wasps; Fig. 2). The probability of visits to plant species from the different altitudinal zones and that to common vs. rare species did not significantly differ within each flower-visitor group (Fig. 2).

\section{Discussion}

\section{Flowering phenology}

In line with results of earlier studies investigating phenological responses of mountain plants to warmer temperatures (Hülber et al. 2010; Scheepens and Stöcklin 2013; Sedlacek et al. 2015), we found pronounced shifts of 2 or more months in flowering phenology of alpine plants growing below their natural altitudinal distribution. One alpine plant species, Draba fladnizensis, even started flowering 4 months earlier (in March) than in its natural habitat (Table S1). For alpine plants, adjusting phenology to ambient climatic conditions is essential to successfully complete their life cycle as the growing season at high elevations is usually short and highly variable (Hülber et al. 2010; Pau et al. 2011; Wolkovich et al. 2014). Therefore, many alpine plants will likely start flowering as early as possible in the season, and also readily shift their flowering onset if the climatic conditions change.

Earlier flowering onset can lead to a prolonged flowering period, to a shorter flowering period or to a shift of the entire flowering period when they also finish flowering earlier (CaraDonna et al. 2014; Dunne et al. 2003; GiménezBenavides et al. 2011; Gugger et al. 2015). A prolonged flowering period can lead to a higher flower number, resulting in more fruits and, therefore, ultimately improve plant fitness (Giménez-Benavides et al. 2011). A shift of the entire flowering period can affect pollination success directly by either disruption of plant-pollinator interactions or allowing the maintenance of such interactions (Hegland et al. 2009; Kudo and Ida 2013; Memmott et al. 2007; Petanidou et al. 2014). It can also affect pollination success indirectly by altered co-flowering patterns in the community influencing competition or facilitation of pollination (Ghazoul 2006; Mitchell et al. 2009). Therefore, phenological changes will likely lead to changes in species interactions, and modify the composition of ecological communities (CaraDonna et al. 2014; Hülber et al. 2010).

As alpine and montane plants had stronger shifts in flowering onset than colline (lowland) plants in the lowland garden (Fig. 1b), our results contradict the previous findings which suggest that the capacity of species from high elevation to respond plastically to changes in temperature are constrained in cold environments. In a recent transplant experiment using $20 \mathrm{mid}$ - and high-elevation alpine species, Gugger et al. (2015) showed that plants from mid and high elevation advanced their flowering onset at a lower and warmer site, but shifts were smaller for high-elevation than for mid-elevation species. Similarly, a transplant experiment by Schmid et al. (2017) using 11 congeneric species pairs found that high-elevation plants shifted their flowering onset 7 days less than low-elevation ones at a lower and warmer site, suggesting that high-elevation plants had reduced plasticity in flowering phenology. Contrastingly, our results suggest that plants from high elevation have higher plasticity than plants from lower elevation. It could be that the heterogeneous habitats in alpine environments select for higher plasticity. Nevertheless, although alpine habitats are frequently assumed to be heterogeneous, rigorous tests using the relevant environmental factors for the traits under study are lacking.

Although a recent observational study of 154 plant species of the Sandhills region of North Carolina shows that rare species generally flower later and have a shorter flowering duration than common species (Ames et al. 2016), our study including 185 plant species showed that rare and common species did not significantly differ in their flowering onset and phenological shift. This suggests that rare species are not less plastic than common species are in adjusting phenologically to a warmer climate. To 


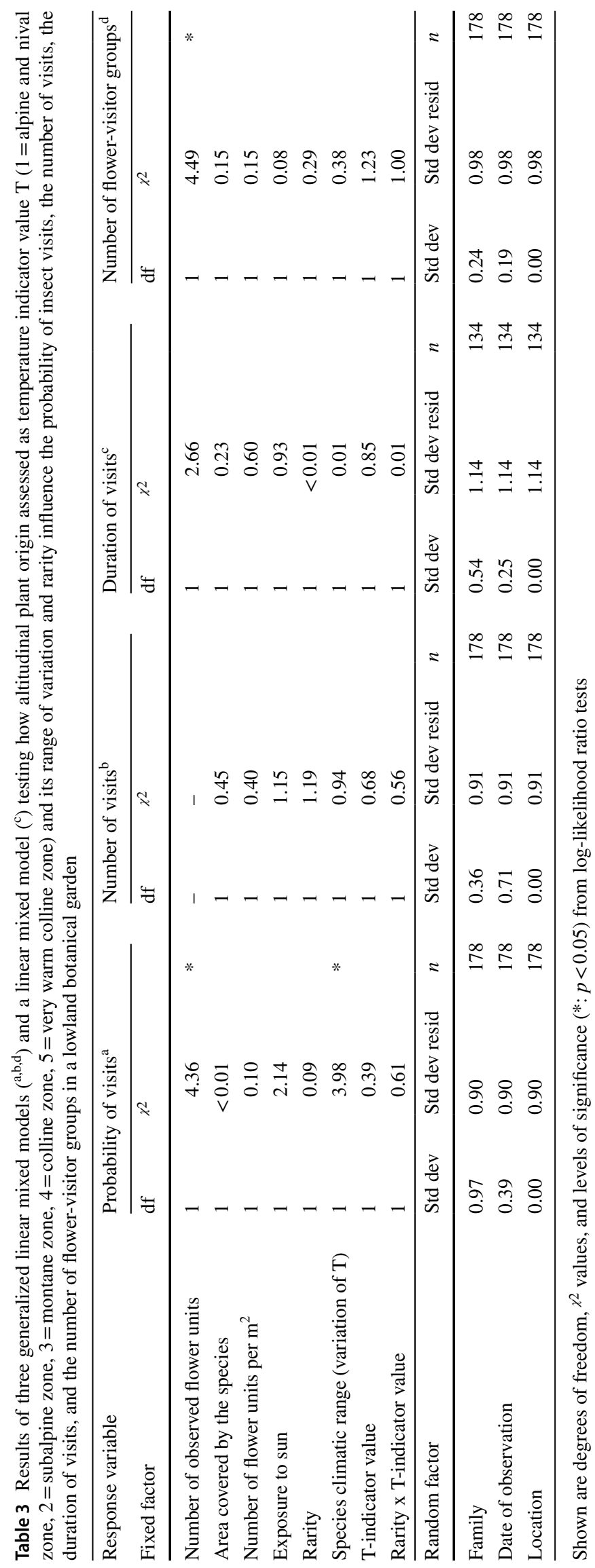




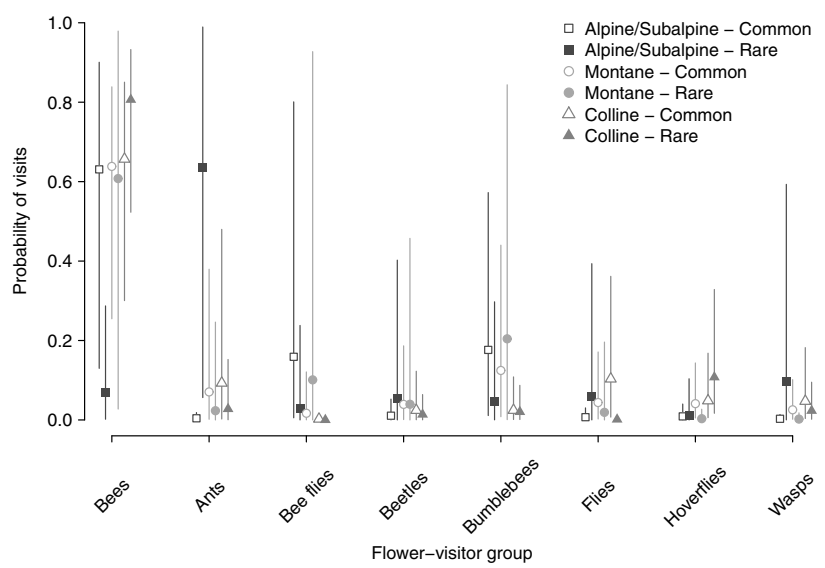

Fig. 2 Probability of visits by different flower-visitor groups to common and rare plant species originating from different altitudinal zones and grown in a lowland botanical garden. Bars indicate $95 \%$ credible intervals of a multinomial logistic regression

maximize the number of rare and common species used in our study, the assessment of plasticity was done at the population rather than the individual level. However, plant populations in botanical gardens tend to be small in general, independent of natural species rarity (Enßlin et al. 2011; Lauterbach et al. 2012). Thus, if bottleneck effects reduced the potential to respond to climatic change, they might have acted similarly for both rare and common species in our botanical garden study.

Contrary to our expectations, we found that species from small climatic ranges were more able to advance flowering onset than species from larger climatic ranges. This discrepancy might be due to the way how climatic range was assessed (Landolt et al. 2010). For example, montane species with a large climatic range might have a similar mean flowering onset in nature and the lowland garden. Nevertheless, among the species that did not shift phenology-the majority of the species in our study $(73.5 \%)$ - most species also had small ranges. Future studies testing the relationship between ecological niche breadth and plasticity should use a finer measure of climatic range, for instance, considering abundance of species rather than occurrence only.

The results of our study suggest that alpine plants will generally respond to climate change by flowering earlier. Whether such a phenological shift will lead to fitness costs (Burgess et al. 2007; Scheepens and Stöcklin 2013) or rather to enhanced plant performance (Cleland et al. 2012; Springate and Kover 2014), increased risk of frost damage (Inouye 2008), temporal mismatches in plant-pollinator interactions (Kudo and Ida 2013; Petanidou et al. 2014) or changes in plant communities (CaraDonna et al. 2014) remains to be further investigated.

\section{Flower visitation}

The number of flower visits, flower-visit duration, and the number of flower-visitor groups did not depend on the natural altitudinal zone of origin of the assessed plants. Altitudinal zone of origin of the species also did not influence the composition of the flower-visitor groups in the lowland botanical garden. Thus, the plant species of alpine and montane origin were able to attract a similar number and type of flower visitors as the plant species from colline (lowland) origin in the Botanical Garden of Bern. This finding is in line with several studies that found a remarkable plasticity of plant-pollinator interactions over time, resulting in novel interactions and switching of interaction partners ("rewiring"; Alarcón et al. 2008; Burkle et al. 2013; Dupont et al. 2009; Petanidou et al. 2008). Thus, plant-pollinator interactions seem to be more flexible than previously thought, and disrupted plant-pollinator interactions due to shifts in phenology or distribution might be replaced by new interactions (Alarcón et al. 2008; Memmott et al. 2007; Petanidou et al. 2008). However, as the botanical-garden pollinator community may not be representative for all lowland pollinator communities, this should be tested at more locations.

We did not detect any significant difference between rare and common plant species in their ability to attract potential pollinators. Furthermore, we found no significant difference in the number of observed flower-visitor groups between the rare and the common plant species. The composition of flower-visitor groups also did not depend on whether a plant species is rare or common. Although rare plant species might appear to be specialized, they might be specialized on abundant and ubiquitous pollinators (Bascompte et al. 2006; Sargent and Otto 2006). However, as we did not determine the flower-visiting insects to the species level, we may not have been able to detect truly specialized interactions between plants and pollinators. Still, our study suggests that rare and common plant species did not differ in their ability to form new plant-pollinator interactions.

In our study, plant species with small climatic ranges were less likely to receive flower visits than species with large ranges (Table 3). This might reflect an association of plants with small climatic ranges to specialized pollinators in nature (Blüthgen et al. 2007). A recent study by Hallmann et al. (2017) showed a decline of 76-82\% of flying insects in protected areas in Germany over 27 years, suggesting an important loss of pollinating insects. Furthermore, because important pollinator species such as bumblebees are predicted to reduce their range under climate change (Ollerton 2017), specialized plant-pollinator interactions might be particularly at high risk. Therefore, a narrow climatic tolerance may constrain the resilience of plants to disrupted plant-pollinator interactions in a warmer climate, as the ability to form novel interactions might be limited. 
If we would have assessed flower visitation more than once per plant species and for a longer time, we might have been able to detect variation in the number of flower visits during the day and during the whole flowering period of the plants. However, by limiting the observation time per species, we were able to include a large number of different plant species, which increases generalizability of the results and is essential for reasons of statistical power (van Kleunen et al. 2014). Although we looked at different visitation variables (incidence of visitation, number and duration of visits, and visitor group), we cannot exclude that the effectiveness of pollination differed between rare and common species and among plants from different elevations. Therefore, as a next step, it would be interesting to test whether flower visits actually lead to pollination and fertilization of the plants, and thus whether the plants can successfully reproduce.

The consequences of disrupted plant-pollinator interactions by phenological or distributional shifts may be mitigated by the flexibility of pollination networks (Alarcón et al. 2008; Memmott et al. 2007; Petanidou et al. 2008). However, the possibility for new plant-pollinator interactions to emerge relies on sufficiently high species diversity (Kaiser-Bunbury et al. 2010). A sufficiently large speciespool offers more options for new interaction combinations than a community with only few species. Thus, even though pollination networks seem to be partly resilient to the loss of existing plant-pollinator interactions, there is no guarantee that the disruption of interactions cannot lead to the extinction of species and the impairment of pollination services eventually, especially in the case of ongoing biodiversity loss (Memmott et al. 2007).

\section{Conclusion}

Our results show that alpine plant species generally flowered earlier when growing below their natural altitudinal distribution regardless of whether they were common or rare. This suggests that alpine plant species generally are able to adjust their phenology to a changing climate. Furthermore, the alpine plant species in our study seemed to be able to attract flower visitors in the lowland as well as lowland species do. Thus, plant-pollinator interactions seem to be flexible, and novel interactions may mitigate the consequences of disrupted plant-pollinator interactions caused by phenological or distributional shifts.

\section{Data availability}

The data generated and analyzed during this study, including $\mathrm{T}$-indicator value, $\mathrm{T}$ range, species Red list status, flowering period in nature, flowering start in the botanical garden, number of flower visits, mean flower visitation duration, and number of flower-visitor groups are included in the electronic supplementary material of this published article (Table S1). Data on the number of flower visits by each flower-visitor group are available from the corresponding author upon request.

Acknowledgements We thank all volunteers who helped with the data collection; the Botanical Garden of Bern for allowing the flower-visitor observations; Corina del Fabbro for statistical advice; Andreas Ensslin and Steffen Boch for helpful comments on the manuscript. M. R. thanks the German Research Foundation DFG for funding (RA 3009/1-1).

\section{Compliance with ethical standards}

Conflict of interest The authors declare that they have no conflict of interest.

\section{References}

Alarcón R, Waser NM, Ollerton J (2008) Year-to-year variation in the topology of a plant-pollinator interaction network. Oikos 117:1796-1807

Ames GM, Wall WA, Hohmann MG, Wright JP (2016) Trait space of rare plants in a fire-dependent ecosystem. Conserv Biol 31:903911. https://doi.org/10.1111/cobi.12867

Anderson JT, Inouye DW, McKinney AM, Colautti RI, Mitchell-Olds T (2012) Phenotypic plasticity and adaptive evolution contribute to advancing flowering phenology in response to climate change. Proc R Soc Lond Ser B Biol Sci 279:3843-3852

Bascompte J, Jordano P, Olesen JM (2006) Asymmetric coevolutionary networks facilitate biodiversity maintenance. Science 312:431-433

Bates D, Maechler M, Bolker B, Walker S (2015) Fitting linear mixedeffects models using lme4. J Stat Softw 67:1-48

Baythavong BS, Stanton ML (2010) Characterizing selection on phenotypic plasticity in response to natural environmental heterogeneity. Evolution 64:2904-2920

Blüthgen N, Menzel F, Hovestadt T, Fiala B, Blüthgen N (2007) Specialization, constraints, and conflicting interests in mutualistic networks. Curr Biol 17:341-346. https://doi.org/10.1016/j. cub.2006.12.039

Burgess K, Etterson J, Galloway L (2007) Artificial selection shifts flowering phenology and other correlated traits in an autotetraploid herb. Heredity 99:641-648

Burkle LA, Marlin JC, Knight TM (2013) Plant-pollinator interactions over 120 years: loss of species, co-occurrence and function. Science 339:1611-1615

CaraDonna PJ, Iler AM, Inouye DW (2014) Shifts in flowering phenology reshape a subalpine plant community. Proc Natl Acad Sci 111:4916-4921

Chevin L-M, Hoffmann AA (2017) Evolution of phenotypic plasticity in extreme environments. Philos Trans R Soc B Biol Sci 372. https ://doi.org/10.1098/rstb.2016.0138

Cleland EE et al (2012) Phenological tracking enables positive species responses to climate change. Ecology 93:1765-1771

Delnevo N, Petraglia A, Carbognani M, Vandvik V, Halbritter AH (2017) Plastic and genetic responses to shifts in snowmelt time affects the reproductive phenology and growth of Ranunculus acris Perspect Plant Ecol Evol Syst. https://doi.org/10.1016/j. ppees.2017.07.005 
Dicks L, Corbet S, Pywell R (2002) Compartmentalization in plantinsect flower visitor webs. J Anim Ecol 71:32-43

Diez JM et al (2012) Forecasting phenology: from species variability to community patterns. Ecol Lett 15:545-553

Dunne JA, Harte J, Taylor KJ (2003) Subalpine meadow flowering phenology responses to climate change: integrating experimental and gradient methods. Ecol Monogr 73:69-86

Dupont YL, Padrón B, Olesen JM, Petanidou T (2009) Spatio-temporal variation in the structure of pollination networks. Oikos 118:1261-1269

Enßlin A, Sandner TM, Matthies D (2011) Consequences of ex situ cultivation of plants: genetic diversity, fitness and adaptation of the monocarpic Cynoglossum officinale $\mathrm{L}$ in botanic gardens. Biol Conserv 144:272-278

Fitter A, Fitter R (2002) Rapid changes in flowering time in British plants. Science 296:1689-1691

Forrest J, Miller-Rushing AJ (2010) Toward a synthetic understanding of the role of phenology in ecology and evolution. Philos Trans R Soc Lond B Biol Sci 365:3101-3112

Ghazoul J (2006) Floral diversity and the facilitation of pollination. J Ecol 94:295-304

Giménez-Benavides L, García-Camacho R, Iriondo JM, Escudero A (2011) Selection on flowering time in Mediterranean high-mountain plants under global warming. Evol Ecol 25:777-794

Gugger S, Kesselring H, Stöcklin J, Hamann E (2015) Lower plasticity exhibited by high- versus mid-elevation species in their phenological responses to manipulated temperature and drought. Ann Bot 116:953-962. https://doi.org/10.1093/aob/mcv155

Hallmann CA et al (2017) More than 75 percent decline over 27 years in total flying insect biomass in protected areas. PLOS One 12:e0185809. https://doi.org/10.1371/journal.pone.0185809

Hegland SJ, Nielsen A, Lázaro A, Bjerknes AL, Totland Ø (2009) How does climate warming affect plant-pollinator interactions? Ecol Lett 12:184-195

Hülber K, Winkler M, Grabherr G (2010) Intraseasonal climate and habitat-specific variability controls the flowering phenology of high alpine plant species. Funct Ecol 24:245-252

Inouye DW (2008) Effects of climate change on phenology, frost damage, and floral abundance of montane wildflowers. Ecology $89: 353-362$

IPCC (2007) Intergovernmental Panel On Climate Change, Fourth Assessment Report, Climate Change 2007: Syntheses Report. UNEP, Geneva

Kaiser-Bunbury CN, Muff S, Memmott J, Müller CB, Caflisch A (2010) The robustness of pollination networks to the loss of species and interactions: a quantitative approach incorporating pollinator behaviour. Ecol Lett 13:442-452

Kudo G, Ida TY (2013) Early onset of spring increases the phenological mismatch between plants and pollinators. Ecology 94:2311-2320

Landolt E (2003) Unsere Alpenflora vol 7. SAC-Verlag Schweizer Alpen-Club, Bern

Landolt E et al (2010) Flora indicativa-ecological indicator values and biological attributes of the flora of Switzerland and the Alps. Haupt, Bern

Lauterbach D, Burkart M, Gemeinholzer B (2012) Rapid genetic differentiation between ex situ and their in situ source populations: an example of the endangered Silene otites (Caryophyllaceae. Bot J Linn Soc 168:64-75

Lázaro-Nogal A, Matesanz S, Godoy A, Pérez-Trautman F, Gianoli E, Valladares F (2015) Environmental heterogeneity leads to higher plasticity in dry-edge populations of a semi-arid Chilean shrub: insights into climate change responses. J Ecol 103:338-350

Lunn DJ, Thomas A, Best N, Spiegelhalter D (2000) WinBUGS-a Bayesian modelling framework: concepts, structure, and extensibility. Stat Comput 10:325-337
Matesanz S, Valladares F (2014) Ecological and evolutionary responses of Mediterranean plants to global change. Environ Exp Bot 103:53-67

Memmott J, Waser NM (2002) Integration of alien plants into a native flower-pollinator visitation web. Proc R Soc Lond Ser B Biol Sci 269:2395-2399. https://doi.org/10.1098/rspb.2002.2174

Memmott J, Craze PG, Waser NM, Price MV (2007) Global warming and the disruption of plant-pollinator interactions. Ecol Lett 10:710-717

Mitchell RJ, Flanagan RJ, Brown BJ, Waser NM, Karron JD (2009) New frontiers in competition for pollination. Ann Bot 103:1403-1413

Moser D, Gygax A, Bäumler B, Wyler N, Palese R (2002) Red List of threatened ferns and flowering plants in Switzerland Bundesamt für Umwelt, Wald und Landschaft, Bern, Zentrum des Datenverbundnetzes der Schweizer Flora. Chambésy, Conservatoire et Jardin Botaniques de la Ville de Genève, Chambésy

Ntzoufras I (2011) Bayesian modeling using WinBUGS, vol 698. Wiley, New Jersey

Ollerton J (2017) Pollinator diversity: distribution, ecological function, and conservation. Ann Rev Ecol Evol Syst 48:353-376. https:// doi.org/10.1146/annurev-ecolsys-110316-022919

Orians GH (1997) Evolved consequences of rarity. The biology of rarity. Springer, Berlin, pp 190-208

Parmesan C (2006) Ecological and evolutionary responses to recent climate change. Annu Rev Ecol Evol Syst 37:637-669

Parmesan C, Yohe G (2003) A globally coherent fingerprint of climate change impacts across natural systems. Nature 421:37-42

Pau S et al (2011) Predicting phenology by integrating ecology, evolution and climate science. Global Change Biol 17:3633-3643

Petanidou T, Kallimanis AS, Tzanopoulos J, Sgardelis SP, Pantis JD (2008) Long-term observation of a pollination network: fluctuation in species and interactions, relative invariance of network structure and implications for estimates of specialization. Ecol Lett 11:564-575

Petanidou T, Kallimanis AS, Sgardelis SP, Mazaris AD, Pantis JD, Waser NM (2014) Variable flowering phenology and pollinator use in a community suggest future phenological mismatch. Acta Oecol 59:104-111

Phillips RD, Peakall R, Hutchinson MF, Linde CC, Xu T, Dixon KW, Hopper SD (2014) Specialized ecological interactions and plant species rarity: the role of pollinators and mycorrhizal fungi across multiple spatial scales. Biol Conserv 169:285-295

R Core Team (2012) A language and environment for statistical computing. R Foundation for Statistical Computing, Vienna

Razanajatovo M, Föhr C, Fischer M, Prati D, van Kleunen M (2015) Non-naturalized alien plants receive fewer flower visits than naturalized and native plants in a Swiss botanical garden. Biol Conserv 182:109-116

Rixen C, Dawes MA, Wipf S, Hagedorn F (2012) Evidence of enhanced freezing damage in treeline plants during six years of $\mathrm{CO}_{2}$ enrichment and soil warming. Oikos 121:1532-1543

Sargent RD, Otto SP (2006) The role of local species abundance in the evolution of pollinator attraction in flowering plants. Am Nat 167:67-80

Scheepens J, Stöcklin J (2013) Flowering phenology and reproductive fitness along a mountain slope: maladaptive responses to transplantation to a warmer climate in Campanula thyrsoides. Oecologia 171:679-691

Schielzeth H (2010) Simple means to improve the interpretability of regression coefficients. Methods Ecol Evol 1:103-113

Schmid SF, Stöcklin J, Hamann E, Kesselring H (2017) High-elevation plants have reduced plasticity in flowering time in response to warming compared to low-elevation congeners. Basic Appl Ecol 21:1-12. https://doi.org/10.1016/j.baae.2017.05.003 
Sedlacek J et al (2015) The response of the alpine dwarf shrub Salix herbacea to altered snowmelt timing: lessons from a multi-site transplant experiment. PLOS One 10:e0122395

Sheth SN, Angert AL (2014) The evolution of environmental tolerance and range size: a comparison of geographically restricted and widespread Mimulus. Evol 68:2917-2931. https://doi. org/10.1111/evo.12494

Springate DA, Kover PX (2014) Plant responses to elevated temperatures: a field study on phenological sensitivity and fitness responses to simulated climate warming. Global Change Biol 20:456-465

Sultan SE (2001) Phenotypic plasticity for fitness components in Polygonum species of contrasting ecological breadth. Ecology 82:328 343. https://doi.org/10.1890/0012-9658(2001)082[0328:PPFFCI ]2.0.CO;2 van Kleunen M, Dawson W, Bossdorf O, Fischer M (2014) The more the merrier: multi-species experiments in ecology Basic. Appl Ecol 15:1-9

Venables W, Ripley B (2002) Modern applied statistics with S. Fourth Edition. Springer, New York

Vilà M, Bartomeus I, Dietzsch AC, Petanidou T, Steffan-Dewenter I, Stout JC, Tscheulin T (2009) Invasive plant integration into native plant-pollinator networks across Europe. Proc R Soc Lond Ser B Biol Sci 276:3887-3893

Wolkovich EM, Cook BI, Davies TJ (2014) Progress towards an interdisciplinary science of plant phenology: building predictions across space time species diversity. New Phytol 201:1156-1162

Zuur A, Ieno E, Walker N, Saveliev A, Smith G (2009) Mixed effects models and extensions in ecology with R. Springer, New York 